\title{
On policy relevance of correct specification for production functions
}

\author{
Isaac D. Essi \\ Centre for Econometric and Allied Research, University of Ibadan, Ibadan, Nigeria \\ \& \\ Department Of Mathematics/Computer Science, Rivers State University of Science \& \\ Technology, Port Harcourt, Nigeria
}

\begin{abstract}
The paper looks at implications of mis-specifications for production functions in econometrics. The paper also considers the role played by production function in economics and how that role may be enhanced when production functions are correctly specified. Production function used here is of the Cobb-Douglas model.
\end{abstract}

Keywords: Correct specification, policy relevance

\section{INTRODUCTION}

Theory and Practice of Econometrics: The three major purposes of conducting an econometric study are structural analysis, forecasting and policy evaluation. They provide according to Intriligator (1978) respectively, the descriptive, predictive and prescriptive uses of econometrics. The level of success to be scored in the realization of these objectives depends on the extent and depth of the researcher's sophistication in econometric theory. Good practice and good theory are Siamese twins. This view is held by Lindley (1983): "Good theory and good practice go hand in hand. Theory that does not have practical application is underdeveloped. Practice that is not supported by a sound theory is often subjective, misleading and inconsistent." Therefore, in the first instance, this research is to boost the on-going interplay in econometrics between sound theory and sound practice.

With a 'full-fledged' econometrics (sound theory and sound practice) on ground, we go on to consider how the subject can enhance the promotion of successful research in economics. There are few principal foci in this regards and three of them are well cited in Formby, Hill and Johnson (1984). The primary intervention of econometrics in economic research is in the selection of statistical methods that adequately reflect how the data were actually generated by an unknown experimental design. The second provision from econometrics is making available non-sample information for incorporation into models. This is important especially in regional and sub-regional studies in Africa where sampling is largely used. What the sample cannot provide, econometrics can. The third is that since economic theory fails almost completely to provide exact functional forms, the possibility and problem of misspecification inevitably comes in and econometric theory provides the analysis of consequences of incorrect assumptions and the invention of procedures for detecting the presence of various misspecifications. The study shall also consider policy issues using production functions under alternative error specifications.

The Role of the Production Function in Economics: Two basic theories in microeconomics are that of utility and production. The first deals with utility-maximising consumer and the second focuses on profit-maximising producer. The entire structure of modern economics rests on these foundations of utility and production. This observation does not end with micro theory by extends to macro theory through aggregate production and consumption functions. The aggregate production analysis offers a systematic description of overall input-output relations in an industry or even an entire economy. Many and useful macroeconomic models, relations and concepts such as potential output, technical change, the investment function and the demand for labour are based on it.

\section{Production function:}

Aggregation, Specification and Policy Issues: Aggregation in economics is an attempt to obtain at macro level a quantitative representation and explanation of whatever phenomenon is observed in micro theory and practice. Although the aggregation process is plagued with an lot of difficulties, Sato (1975) has shown that under certain conditions, aggregate production functions do exist and so can 
be constructed. There are some reasons for seeking for macro relations for their micro equivalents. Some of these reasons are elaborately mentioned in Sato (1975). For instance, the general equilibrium theory is capable of furnishing us with relevant interactions of micro units from which we can obtain macroeconomic movements. However, one observes with Sato that the general equilibrium theory is not yet developed to the point of giving us broad relations among macro variables. This need is met by the use of aggregative functions. In addition, economic data are not available in all required details to make possible the construction of complete micro models of the economy.

The aggregation of micro relationship is essentially the aggregate of micro variables over micro units. The aggregation process assumes already the exhibition of rational behaviour of micro units. It is therefore wrong according to Sato (1975) to infer macroeconomic behaviour by analogy solely from equivalent micro behaviour. This is in line with the observation of Walters (1963): that firms are enjoying increasing returns to scale does not imply that the industry (or the economy) as a whole is expecting economies of scale. Empirical studies of the aggregate production function will throw in some amount of light on macroeconomic behaviour. Finally, and very relevant to this study is that of specification of production function. The production function may be wrongly specified and the form of mis-specification at micro level may not be exactly as it is at the macro level. For this reason and others cited earlier, policies of government on production to individual firms may not be useful for the whole economy. Policies of the authorities to industries or the economy should come after a rigorous and systematic aggregation in the face of possible misspecification. We consider subsequently more policy issues relevant to this study.

The Cobb-Douglas production function (omitting the error term) is of the form

$$
\mathrm{y}=\theta_{1} \mathrm{~K}^{\theta_{2} \mathrm{~L}} \theta_{3}
$$

the constant $\theta_{1}$ in cross-section stands for efficiency. States, say, in an economy like Nigeria could have the same $\theta_{2}$ and $\theta_{3}$ for a given industry (for example rice production in Kebbi and Niger States) therefore they apply the same techniques but the state with higher value of $\theta_{1}$ would produce more, for every combination of inputs, than the other state: So $\theta_{1}$ expresses the relative efficiency of combining the given inputs. The parameter $\theta_{1}$ in essence, can be used as an indicator of the general state of technology. Policy of government in the agricultural sector of the economy should include advising states with lower $\theta_{1}$ to consider as one of the priorities using judiciously some funds in improving the technology level in production. This reasoning similarly applies when we compare efficiencies of two countries for a given industry, for example, palm oil production in Nigeria and Malaysia. It is obvious at the moment judging from the present economic situation that Nigeria needs a higher level of technology in this case.

The production function is also known to exhibit some returns-to-scale phenomena at some points under certain conditions. These returns-to-scale phenomena plays significant role in the policy of resource allocation and taxation of industries. Marshall, as cited in Bhatia (1994) recommends that the output of an industry operating under diminishing returns should be taxed, while the output of an industry under increasing returns should be subsidized. An industry with constant returns is neither to be taxed nor subsidized. Marshalian reasoning is that diminishing returns industry should be discouraged and increasing returns industry should be encouraged to produce. These suggestions as observed in Bhatia (1994) do lead to the conclusion that authorities may be able to wisely adopt a set of indirect taxes on a selective basis for obtaining a desired shift from the current allocation of production resources. Such an option is of great policy relevance in a country like Nigeria where investment in high priority industries is to be encouraged.

Apart from exhibiting returns-to-scale phenomena in certain cases, the production function shows the property of substitutability of inputs for one another. A local measure of such substitutability is the elasticity of substitution. It is normally denoted by $\sigma$. The elasticity of substitution $\sigma$ is defined as the ratio of the proportionate change in the ratio of factor inputs to the proportionate change in the ratio of marginal products. That is

$$
\sigma=\frac{d[\ln (K / L)]}{d\left[\ln \left(M P_{L} / M P_{K}\right)\right]}
$$

where $M P_{L}$ and $M P_{K}$ are respectively marginal products with respect to labour and capital. 
In the case of perfect competition and profit maximisation, the ratio of the marginal products is the ratio of factor prices. Thus

$$
\sigma=\frac{d[\ln (K / L)]}{d[\ln (w / r)]}
$$

The elasticity of substitution is thus a measure of how quickly factor proportions change for change in relative factor prices. The letters $w$ and $r$ denote respectively labour and capital prices. The value of $\sigma$ lies between 0 and $\infty$. The value of $\sigma$ has policy relevance in economics. However, in the CobbDouglas case, since its value is unity, one may think that there is not much one can deduce from $\sigma$ as far as policy is concerned. With the right specification, the value of $\sigma$ is unity. If the value of $\sigma$ is significantly different from unity, this points to the fact that there can be a possible form of mis-specification. Some works on mis-specification are cited in Essi (2000), Essi and lyaniwura (2007), Essi, Iyaniwura and Ojekudo (2007) ; and Essi $(2009,2010)$. These earlier results, show that the consequence is more serious when a multiplicative error plagued data set is fitted with an additive error based model than viceversa Therefore in this circumstance, the values of other model parameters should not be relied upon heavily in policy making and implementation. In Essi, Olaomi and Nwabueze (2010); and Essi, Onwuchekwa and Chikwendu (2010), Monte Carlo simulation and forecast are considered using correctly specified nonlinear production functions and are more reliable for use in policy formulation and implementation.

\section{CONCLUSION}

The sole aim of economic policy is the utilization of economic principles in solving or alleviating certain problems and furthering the actualization of the overall good of the economy. An accurate prediction is obviously needed if we want to influence or control some economic events. In the event of a possible undesirable outcome that is expected to occur at a future date or period from forecasting techniques, some judicious compensation adjustment could be made in advance. However, basing policies on estimated parameters and/or prediction values of variables in production function is not enough. Some other criteria or issues in the economy should be brought in when considering policies. For instance, one of the outstanding drawbacks in implementing Marshalian suggestions on taxation of industries using returns-to-scale phenomena is that of a possible estimation of production functions in the presence of inappropriate error term or some other form of mis-specification. With this in mind, reliance only on returns-to-scale phenomena for policy on taxation to producing industries is not enough. Again, since increase returns in individual firms do not imply that the industry or the whole economy will enjoy economies of scale, the application of Marshalian reasoning on macro level should await empirical construction and careful use of aggregate production function.

\section{ACKNOWLEDGEMENT}

I am very grateful to African Economic Research Consortium and Centre for Econometrics and Allied Research for research grants and support that make this paper possible.

\section{REFERENCES}

Bhatia, H.L. (1994), Public Finance, $18^{\text {th }}$ Edition. New Delhi: Vikas Publishing House PVT Limited.

Essi, I. D., 2002 "Econometric Models with Mis-specified Error Terms "A Abacus(Journal of the Mathematical Association of Nigeria), Vol 29 (2), $152-160$.

Essi, I.D. and Iyaniwura , J. O.(2007) On Robustness and Choosing Between Two Nonlinearities. Advances and Applications in Statistics. 7(3), 451-462.

Essi, I. D., Iyaniwura, J. O. and Ojekudo N. A., (2007)“ On Multicollinearity in Nonlinear Econometric Models with Mis- specified Error Terms in Small Samples"International Journal of Statistics and Systems(IJSS)Vol. 2(1), 41-48.

Essi, I. D.(2009) Computing Leaf Rectangularity Index under Alternative Error Specifications AMSE Journal of Modeling C Vol. 70(1), 67 -79

Essi, I. D.,(2010) Computing Leaf Rectangularity Index: An Estimation Problem When the Parameter is a Norm of a Vector. African Journal of Mathematics and Computer Science Research, 3(7), 79-82.

Essi, I. D, O. Olaomi , and J.C. Nwabueze,(2010) “ On Monte Carlo Forecast of Production using Nonlinear Econometric Models" African Journal of Mathematics andComputer Science Research, 3 (9), 199-205.

Essi, I. D., E. N. Onwuchekwa and G. C. Chikwendu,(2010) " On Appraising Monte Carlo Forecast of Production in Nonlinear Econometric Models" African Journal of Mathematics and Computer Science Research, 3 ( 8), 179-185. 
Fomby, T.B., R.C. Hill and S.R. Johnson (1984), "Advanced Econometrics" Springer-Verlag, New York Inc.

Intriligator, M.D. (1978), "Econometric Models, Techniques, and Applications",Engle Cliffs, New Jersey PrenticeHall.

Lindley, D.V. (1983), "Theory and Practice of Bayesian Statistics, The Statistician 32, 1 - 11.

Sato, K. (1975), Production Functions and Aggregation. Amsterdam, North-Holland Publishing Company.
Walters, T. D. (1963), "Production and Cost Functions: An Econometric Survey", Econometrics, 31: 1- 66.

Zarembka, P. (1966), "Manufacturing and Agricultural Production functions and International Trade", Journal of Farm Economics,47, 952-956.

Zarembka, P. (1974), "Transformation of Variables in Econometrics". In Frontiers in Econometrics, Edited by P. Zarembka, New York Academic Press. 81 - 104. 